\title{
BIOACTIVE LIPIDS, ANTIBACTERIAL, HYPOGLYCAEMIC, AND ANTIOXIDANT POTENTIALS OF IMMATURE AND MATURE VICIA FABA L. SEEDS CULTIVATED IN TUNISIA
}

\author{
A. FerChichi ${ }^{\mathrm{a}, \mathrm{b} *}$, S. HarRabi ${ }^{\mathrm{b}}$, M. FeKr ${ }^{\mathrm{b}}$ and H. Fellah ${ }^{\mathrm{b}}$ \\ ${ }^{\mathrm{a}}$ Faculty of Science, University of Tunis El Manar, 1007, Tunis. Tunisia \\ ${ }^{\mathrm{b}}$ Laboratory of Clinical Biochemistry, LR99ES11, Faculty of Medicine, University of Tunis E1 Manar, 1007, \\ Tunis. Tunisia
}

(Received: 22 November 2019; accepted: 19 March 2020)

\begin{abstract}
Both the immature and mature Vicia faba L. seeds are used for human consumption. However, there is a lack of information on the phytochemical composition and the potent biological properties of the immature seeds. The aim of the present study was to establish the profile of bioactive lipids as well as the antibacterial, antioxidant, and $\alpha$-amylase and $\alpha$-glucosidase inhibitory capacities of the immature and mature Vicia faba L. seeds. The studied petroleum ether extracts contain different bioactive compounds such as $\beta$-sitosterol, lupeol, $\beta$-amyrin, $\alpha$-tocopherol, and $\gamma$-tocopherol. The extracts of the immature seeds exhibited higher antioxidant and antibacterial activities than those of mature ones. All tested extracts exerted higher inhibition on $\alpha$-glucosidase than $\alpha$-amylase. The immature seeds appeared as promising sources of natural antioxidants, antibacterial compounds, and $\alpha$-amylase and $\alpha$-glucosidase inhibitors. Thus, the immature Vicia faba L. seeds have a great potential as functional foods providing health beneficial properties.
\end{abstract} inhibitors

Keywords: Vicia faba L., immature seeds, bioactive lipids, antibacterial activity, natural antioxidants, enzyme

Human pancreatic $\alpha$-amylase and $\alpha$-glycosidase catalyses the hydrolysis of starch to glucose and their activity in the small intestine leads to hyperglycaemia. Thus, the inhibition of $\alpha$-amylase and $\alpha$-glycosidase has been adopted as a therapeutic strategy for the treatment of type-2 diabetes (Lu et al., 2018). The synthetic inhibitors of these enzymes are not sitespecific and have various side effects compared to natural inhibitors (Lu et al., 2018). Antioxidant compounds provide health benefits by preventing oxidative stress related diseases. Recently, there is a growing demand for natural antioxidants due to both consumers' preference and side effects linked with the use of synthetic antioxidants. On the other hand, the emergence of bacterial resistance to existing antibiotics has led to search of new antibacterial substances, especially from natural sources (BEREKSI et al., 2018). Therefore, there is a high interest in the evaluation of the antibacterial and antioxidant capacities of different plant extracts, which were thought to be natural sources containing different bioactive compounds including phenolic and unsaponifiable compounds. Unsaponifiables such as phytosterols and tocopherols are known to have many significant biological properties (SHAHZAD et al., 2017).

Vicia faba L. is an economically important legume species and is gaining growing interest worldwide for health benefits as human food. Different nutritional benefits have been reported for faba beans (HedLEY, 2001; Lu et al., 2018; MALENČIć et al., 2018). The dietary

* To whom correspondence should be addressed.

Phone: +216 27737443; e-mail: azza_f@hotmail.fr 
quality of faba bean seeds depends on the concentration and composition of bioactive microconstituents, which are affected by several factors including cultivars, maturity stage, and cooking (BoukHANOUF et al., 2016; Lu et al., 2018). Nevertheless, much less is known about the bioactive lipid constituents, antibacterial, and hypoglycaemic capacities of the immature Vicia faba seeds. Therefore, the aim of this study was to establish and compare the profile of minor bioactive lipids as well as the antibacterial, antioxidant, and enzyme inhibitory capacities of immature and mature Vicia faba seeds.

\section{Materials and methods}

In this study, two cultivars of faba bean var. major (Vicia faba L.), Mamdouh and Malti, were used. The studied seeds were certified by the National Institute for Agronomic Research (Tunisia). Seeds were cultivated during the season 2014-2015 and were collected at 78 (immature) and 98 (mature) days after flowering.

All chemicals were obtained from Loba Chemie (India and Spain) and from SigmaAldrich Canada Ltd (Oakville, ON, Canada).

\subsection{Seed lipid extraction, saponification and thin layer chromatography}

The oils were extracted using petroleum ether in Soxhlet extractor for $5 \mathrm{~h}$. The saponification steps and the thin layer chromatography analysis of unsaponifiables were done according to previous reports (HARRABI et al., 2007).

\subsection{Gas chromatography-mass spectrometry analysis}

Sterol and alcohol fractions were silylated and injected to GC-MS (Agilent 5977B; HP-5 column $30 \times 0.25 \mathrm{~mm}, 0.25 \mu \mathrm{m}$ film thickness) following the method of HARRABI and coworkers (2007).

\subsection{Analysis of tocopherols by HPLC}

Tocopherols were analysed according to the method described by DEIANA and co-workers (2002). The separation of tocopherol isomers was accomplished on an Atlantic column $(4.6 \times 150 \mathrm{~mm}, 5 \mu \mathrm{m})$.

\subsection{Antioxidant activity}

The DPPH radical scavenging capacity of the lipid extracts was assessed as described by HARRABI and co-workers (2018). The ORAC and ABTS assays were carried out by the method described previously by BouDJOU and co-workers (2013), with slight modifications.

\subsection{Antibacterial activity}

The antibacterial activity of the different extracts was determined using the agar well diffusion method. The bacterial strains used included two Gram positive bacteria (Staphylococcus aureus ATCC 25923 and Listeria innocua CLIP 74915) and two Gram negative bacteria (Salmonella enterica subsp. arizonae CIP 81-3 and Escherichia coli ATCC 25922). 


\subsection{In vitro hypoglycaemic activity}

To determinate the $\alpha$-amylase and $\alpha$-glucosidase inhibitory capacities, we used the reported method of Telagari and Hullatti (2015), with some modifications.

\subsection{Statistical analysis}

Samples were analysed in triplicate, and one way analysis of variance (ANOVA) was performed using SPSS Statistics version 23 Software.

\section{Results and discussion}

\subsection{Bioactive lipids content}

As reported in Table 1, the total lipid content of mature seeds was slightly higher for Mamdouh cultivar $(1.22 \%)$ compared to Malti cultivar $(0.60 \%)$. The observed values were lower than those (1.2-4\%) reported by HEDLEY (2001). Lipid contents are influenced by various factors such as genetic, environmental, and geographic conditions (HARRABI et al., 2015). Moreover, the immature seeds were richer in unsaponifiable lipids than the mature ones. Similarly, unsaponifiable contents were higher in immature corn kernel (HARRABI et al., 2007). Considering the fact that unsaponifiable fraction contains mainly sterols, the decline in the total unsaponifiables was mainly linked to decrease in the total sterol content. This result could be explained by the conversion of sterols to steroidal hormones, which regulate the growth of immature tissue.

Table 1. Total lipid and total unsaponifiable matter contents of the immature and mature faba bean seeds

\begin{tabular}{lccccc}
\hline Maturity stage & \multicolumn{2}{c}{ Mamdouh cultivar } & & \multicolumn{2}{c}{ Malti cultivar } \\
\cline { 2 - 3 } \cline { 5 - 6 } & Oil content & Unsaponifiable content & & Oil content & Unsaponifiable content \\
\hline Immature & $1.1 \pm 0.17$ & $2.66 \pm 0.36$ & & $1.2 \pm 0.3$ & $3.10 \pm 0.17$ \\
Mature & $1.22 \pm 0.02$ & $1.53 \pm 0.02$ & & $0.6 \pm 0.26$ & $1.24 \pm 0.03$ \\
\hline
\end{tabular}

Notes: oil content expressed as $\mathrm{g} / 100 \mathrm{~g}$ of dry seeds. Unsaponifiable content expressed as $\mathrm{g} / 100 \mathrm{~g}$ of oil. Values are represented as means $\pm \mathrm{SD}$ of triplicates

\subsection{Sterols composition}

The total sterol contents of immature Vicia faba L. seeds $\left(1.3-2.96 \mathrm{mg} \mathrm{g}^{-1}\right.$ of oil) were higher than those of mature seeds $\left(0.25-0.82 \mathrm{mg} \mathrm{g}^{-1}\right.$ of oil) (Fig. 1). The observed result could be explained by the fact that the biosynthesis of sterols occurred in the early stages of the fruit development. Physiologically, phytosterols are essential components of cellular membranes; they regulate membrane fluidity and permeability. ZHOU and co-workers (2019) suggested that phytosterols may play a significant role in the performance of immature seeds and in plant adaptation to temperature. At the early stages of plant development, accumulation of phytosterol is crucial for physiological maturation processes and resistance to biotic stress.

Three compounds were identified by GC-MS, which are the three biosynthetic final products in the phytosterol pathway: $\beta$-sitosterol, campesterol, and stigmasterol. At both 
immature and mature stages, the relative percentage of $\beta$-sitosterol is more than $83 \%$ of the total sterols, followed by campesterol (8.91-11.2\%) and stigmasterol (2.84-5.29\%) (Fig 1B). This latter compound plays a key role in innate immunity to combat biotic stresses (ZHOU et al., 2019).
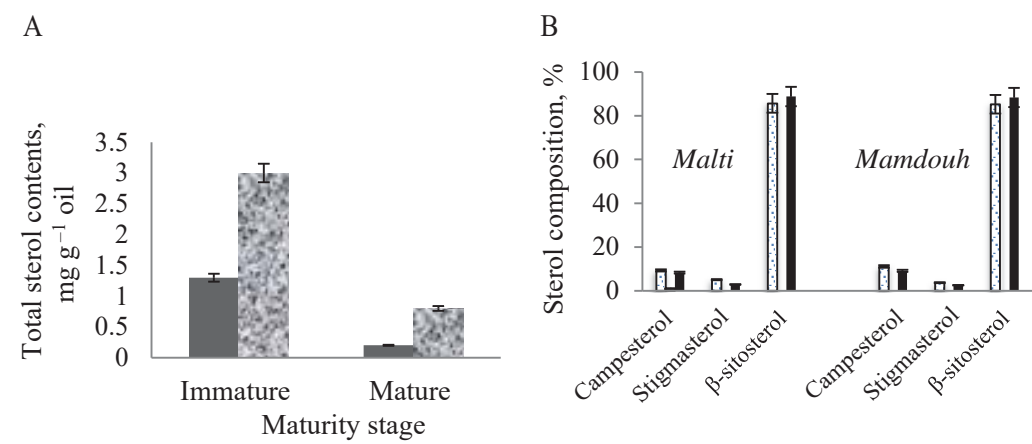

Fig. 1. Sterol contents (A) and composition (B) of the immature and mature faba bean seeds A: a: Mamdouh; a: Malti; B: So: Immature; $\mathbf{a}:$ mature

\subsection{Terpene and aliphatic alcohols composition}

To the best of our knowledge, the alcoholic profile of Vicia faba L. seeds has never been previously reported. The GC-MS analysis of terpene alcohol fraction of the studied oil samples revealed the presence of two pentacyclictriterpene alcohols, $\beta$-amyrin and lupeol, and one non-cyclic diterpene alcohol, phytol. For both cultivars, the mature seeds had higher total terpene alcohol contents $\left(0.73-1.53 \mathrm{mg} \mathrm{g}^{-1}\right.$ of oil) than those of immature seeds $(0.58-$ $1.23 \mathrm{mg} \mathrm{g}^{-1}$ of oil) (Fig. 2A). The terpenes play key role in plant defences against environmental stresses (BHARAT \& RAM, 2015). In the immature faba bean seeds, $\beta$-amyrin was found to be the most abundant compound (76.44-80.65\%), followed by phytol (7.96-12.64\%) and lupeol (10.69-11.32\%) (Fig. 2B). The terpenic alcohol composition of faba bean seeds was different from those of other plant seeds (HARRABI et al., 2007). Considering the fact that lupeol and $\beta$-amyrin have the same precursor. 2,3(S)-oxidosqualene (BHARAT \& RAM, 2015), we suggested that this latter compound was mainly converted in to $\beta$-amyrin in developing faba bean seeds.
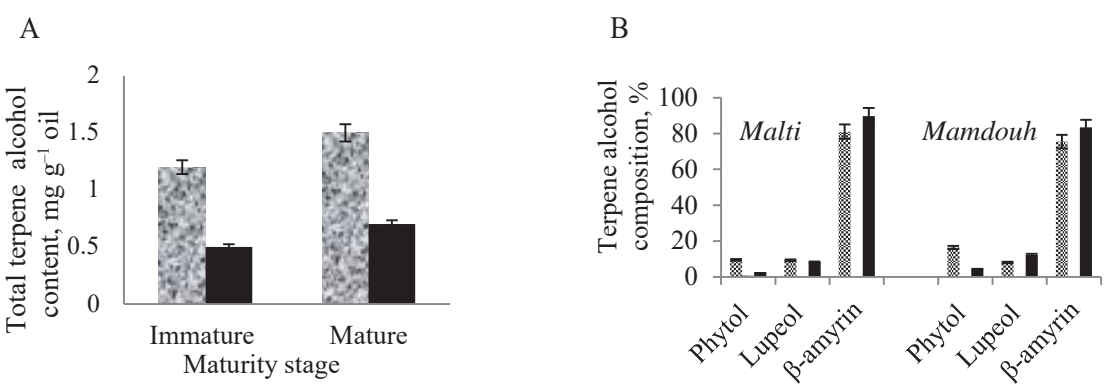

Fig. 2. Terpene alcohol contents (A) and composition (B) of the immature and mature faba bean seeds A: :: Mamdouh; a: Malti; B: $\mathbf{s}:$ Immature; $\mathbf{m}:$ mature 
GC-MS analysis revealed that the aliphatic alcohol fraction contained three compounds, namely tetradecanol (C14), hexadecanol (C16), and octadecanol (C18). As shown in Figure $3 \mathrm{~A}$, the total aliphatic alcohol contents were affected by maturity. For both cultivars, the mature seeds showed the highest total aliphatic alcohol contents (4.03-5.38 mg g $\mathrm{g}^{-1}$ of oil). A similar result was observed for milk thistle seeds (HARRABI et al., 2018). At both maturity stages, the major compound was tetradecanol (46.71-64.38\%) for Malti and hexadecanol (57.48-58.64\%) for Mamdouh (Fig. 3B).
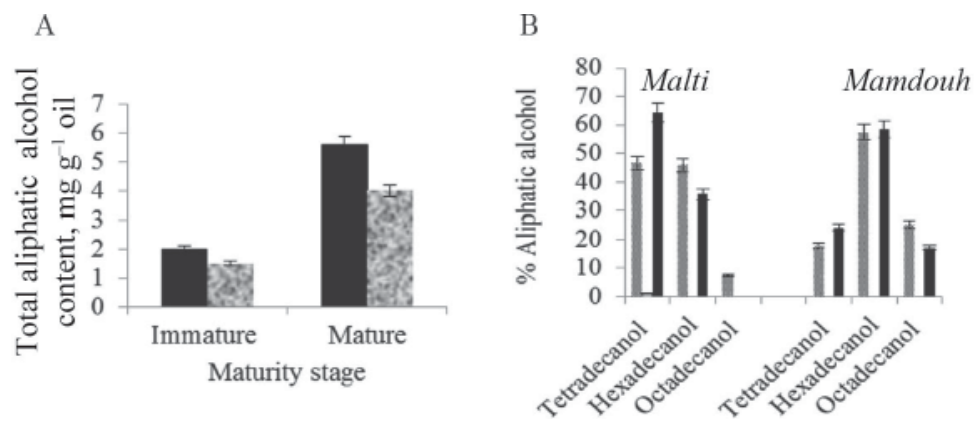

Fig. 3. Aliphatic alcohol contents (A) and composition (B) of the immature and mature faba bean seeds A: a: Mamdouh; ㅁ: Malti; B: Es: Immature; $\mathbf{n}:$ mature

\subsection{Tocopherol composition}

Most literature studies report the tocopherol contents of mature Vicia faba L. seeds, whereas no information is available on immature seeds, despite their importance in the daily diet in several Mediterranean countries (De CiLLIs et al., 2019). In the analysed oil samples, the total

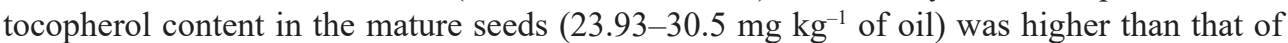
immature seeds (1.6-6.3 mg kg-1 of oil) (Fig. 4A). BELO and co-workers (2017) reported that when oil accumulation rate increased, the rate of tocopherol accumulation also increased. Tocopherols supply plants with antioxidant capacity and offer fluidity and flexibility to cell membranes (ZHOU et al., 2019). At both maturity stages, the most abundant tocopherol isomer was $\gamma$-tocopherol (87.69-98.13\%) followed by $\alpha$-tocopherol (1.85-12.3\%) (Fig. 4B). This result is likely due to the availability of $\gamma$-tocopherol methyl-transferase enzyme, which converts $\gamma$-tocopherol to $\alpha$-tocopherol. The high level of $\gamma$-tocopherol may contribute to the health benefits offered by Vicia faba L. seeds. It has been suggested that $\gamma$-tocopherol was more effective than $\alpha$-tocopherol in the prevention of various diseases (JIANG et al., 2001).

\subsection{Antioxidant activities of Vicia faba L. seed lipids}

The lipid extract of immature faba bean seeds exhibited higher DPPH scavenging effect (61-69.83\%) than the mature seeds (51.88-64.59\%) (Fig. 5A). Similarly, the highest ABTS values $(50.75-54.94 \%)$ were observed in the immature seeds. BouKHANOUF and co-workers (2016) reported that the acetone extract of immature faba bean seeds showed also higher DPPH scavenging activity than the mature ones. For both cultivars, the ORAC values were slightly higher for immature seeds $(2.18-2.52 \mu \mathrm{mol} \mathrm{TE} / \mathrm{mg}$ oil) compared to mature seeds (2.41-2.63 $\mu \mathrm{mol} \mathrm{TE} / \mathrm{mg}$ oil) (Fig. 5B).The antioxidant potential of lipid extracts could be linked to their amounts of unsaponifiable compounds (HARRABI et al., 2018). 

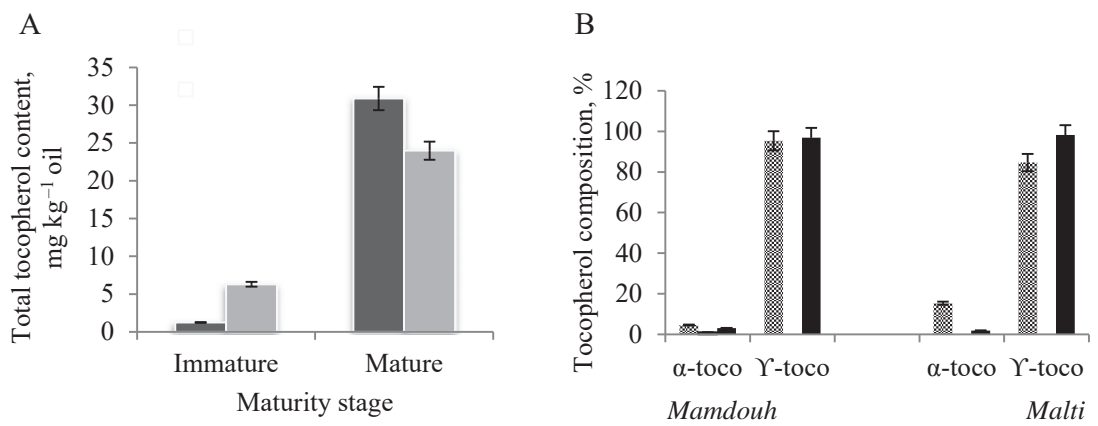

Fig. 4. Tocopherol contents (A) and tocopherols composition (B) of the immature and mature faba bean seeds

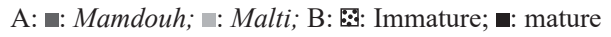

A



B

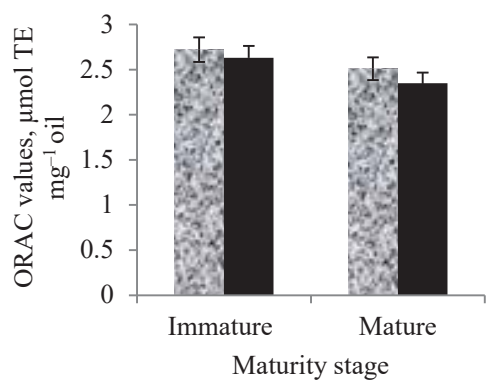

Fig. 5. Antioxidant activity of lipidic fraction extracted from immature and mature faba bean seed (DPPH, ABTS scavenging capacity (\%), and oxygen radical absorbance capacity (ORAC) values expressed as $\mu$ mol of Trolox Equivalents/mg oil).

A: : Immature; mature; B: : Mamdouh; : Malti

\subsection{Antibacterial activity}

The methanolic extracts of immature Vicia faba seeds have a higher activity than those of mature seeds (Table 2). This result suggests that immature seeds are richer in natural compounds with antibacterial activity than mature seeds. With the exception of L. innocua, the tested bacteria were sensitive to the methanolic extracts of immature seeds. The values of inhibition zones of those extracts were more pronounced against $S$. aureus than $S$. enterica and $E$. coli. Similarly, the extract of pods of green faba bean showed antibacterial activity against $B$. subtilis $(12 \mathrm{~mm})$ and E. coli $(11 \mathrm{~mm})$ (CHAURASIA \& SAXENA, 2012). The methanolic extracts of the studied mature seeds did not show notable zones of inhibition. Conversely, there are reports in the literature, where the extracts of mature faba bean seeds exhibited different levels of antibacterial activity (PRABAKARAN et al., 2016). The reason for these differences might be ascribed to differences in the chemical composition of these extracts and in the sensitivity of the tested bacteria. 
Table 2. Antibacterial activity of methanol extracts of the immature and mature faba bean seeds

\begin{tabular}{lcccc}
\hline Vicia faba seeds & \multicolumn{4}{c}{ Zone of inhibition $(\mathrm{mm})$} \\
\cline { 2 - 5 } & Staphylococcus aureus & Salmonella enterica & Escherichia coli & Listeria innocua \\
\hline Immature Mamdouh seeds & $10.2 \pm 0.75$ & $4 \pm 0.5$ & $6 \pm 0.2$ & - \\
Mature Mamdouh seeds & $0.13 \pm 0.05$ & - & - & - \\
Immature Malti seeds & $8.5 \pm 0.5$ & $0.5 \pm 0.11$ & $0.9 \pm 0.86$ & - \\
Mature Malti seeds & $0.3 \pm 0.1$ & - & - & - \\
Streptomycin & 18 & 10.3 & 18.7 & 13 \\
\hline
\end{tabular}

Values are represented as means $\pm \mathrm{SD}$ of triplicates

\section{7. $\alpha$-Amylase and $\alpha$-glucosidase inhibitory capacities of Vicia faba $L$. seed extracts}

The methanolic extract of immature and mature Vicia faba L. seeds showed notable inhibition activity of $\alpha$-amylase and $\alpha$-glucosidase in vitro (Table 3 ). The methanolic extracts of immature faba bean seeds exhibited the highest $\alpha$-amylase and $\alpha$-glucosidase inhibitory activity. Surprisingly, the inhibitory effects of the methanolic extracts of immature Mamdouh seeds against $\alpha$-amylase (17.74-41.31) and $\alpha$-glucosidase (35.22-55.71) were even higher than those of the acarbose (17.86 $\pm 0.61-32.82 \pm 0.87)(30.96-41.12)$ for both tested concentrations $\left(0.5 \mathrm{mg} \mathrm{ml}^{-1}\right.$ and $\left.1 \mathrm{mg} \mathrm{ml}^{-1}\right)$. The methanolic extracts of the immature Vicia faba seeds efficiently inhibited $\alpha$-glucosidase more than $\alpha$-amylase. The $\alpha$-amylase and $\alpha$-glucosidase inhibitory capacities of Vicia faba seeds are comparable to those of Euphorbia hirta, which has been described as antidiabetic plant (MANJUR et al., 2016). The hypoglycaemic effect could be correlated to the phenolic and terpenoid contents of the plant extract (QUAN et al., 2019). Inhibitors of $\alpha$-amylase and $\alpha$-glycosidase delay carbohydrate digestion, which reduces the absorption rate of glucose and decreases the postprandial hyperglycaemia. Thus, immature faba bean seeds consumption could have potential role in control of blood glucose level and their methanolic extract could replace synthetic inhibitors (acarbose and miglitol).

Table 3. $\alpha$-Amylase and $\alpha$-glucosidase inhibitory capacities (\%) of faba bean seed extracts

\begin{tabular}{lccc}
\hline Tested extracts & $\begin{array}{c}\text { Concentration, } \\
\mathrm{mg} \mathrm{ml}^{-1}\end{array}$ & $\begin{array}{c}\text { \% inhibition } \\
\text { of } \alpha \text {-amylase }\end{array}$ & $\begin{array}{c}\text { \% inhibition of } \\
\alpha \text {-glucosidase }\end{array}$ \\
\hline Immature Malti seeds & 0.5 & $16.29 \pm 3.76$ & $19.7 \pm 2.58$ \\
Mature Malti seeds & 1 & $34.17 \pm 1.12$ & $35.99 \pm 4.71$ \\
Immature Mamdouh seeds & 0.5 & $13.77 \pm 3.02$ & $17.15 \pm 0.26$ \\
Mature Mamdouh seeds & 1 & $23.38 \pm 4.84$ & $33.71 \pm 2.66$ \\
& 0.5 & $17.74 \pm 1.53$ & $35.22 \pm 1.93$ \\
Acarbose (standard) & 1 & $41.31 \pm 3.81$ & $55.71 \pm 2.35$ \\
& 0.5 & $15.32 \pm 1.7$ & $31.18 \pm 1.26$ \\
& 1 & $30.14 \pm 1.43$ & $49.00 \pm 3.69$ \\
& 0.5 & $17.86 \pm 0.61$ & $30.96 \pm 0.25$ \\
\hline
\end{tabular}

Values are represented as means $\pm \mathrm{SD}$ of triplicates 


\section{Conclusions}

This study was aimed to establish the phytochemical composition, antibacterial, antioxidant, and enzyme inhibitory effects of immature and mature Vicia faba seeds. Our result revealed that the immature faba bean seeds are rich sources of bioactive lipid compounds. As compared to the extracts of the mature faba bean seeds, the extracts of the immature seeds possessed the highest antioxidant capacity and antibacterial effect against Staphylococcus aureus. All tested extracts showed a potential in $\alpha$-glucosidase inhibition. This could be attributed to the difference in their levels of bioactive compounds, which might be responsible for the pharmaceutical proprieties of seeds. Our data help to understand the nutritional benefits of Vicia faba seeds and that they are useful for application in the food industries and pharmaceutics.

The authors thank Prof. Farah Hosseinian and Karl WASSLEN (Carleton University, Canada) for facilitating the GCMS analysis of oil samples. They thank also the Ministry of Higher Education and Scientific Research of Tunisia for the financial support.

\section{References}

Belo, R.G., Nolasco, S., Mateo, C. \& Izquierdo, N. (2017): Dynamics of oil and tocopherol accumulation in sunflower grains and its impact on final oil quality. Eur. J. Agron., 89, 124-130.

Bereksi, M.S., Hassaïne, H., BeKhechi, Ch. \& Abdelouahid, D.E. (2018): Evaluation of antibacterial activity of some medicinal plants extracts commonly used in Algerian traditional medicine against some pathogenic bacteria. Pharmacogn. J,. 10, 507-512.

Bharat, S. \& RAM, A.S. (2015): Plant terpenes: defense responses, phylogenetic analysis, regulation and clinical applications. 3 Biotech., 5, 129-151.

Boudjou, S., Оомah, B.D., Zaidi, F. \& Hosseinian, F. (2013): Phenolics content and antioxidant and antiinflammatory activities of legume fractions. Food Chem., 138, 1543-1550.

Boukhanouf, S., Louaileche, H. \& Perrin, D. (2016): Phytochemical content and in vitro antioxidant activity of faba bean (Vicia faba L.) as affected by maturity stage and cooking practice. Int. Food Res. J., 23, 954-961.

Chaurasia, S. \& Saxena, R. (2012): Antibacterial activity of four different varieties of green beans. Res. J. Pharm. Biol. Chem. Sci., 3, 70-74.

De Cillis, D.C., Leoni, B., Massaro, M., Renna, M. \& Santamaria, P. (2019): Yield and quality of faba bean (Vicia faba L. var. major) genotypes as a vegetable for fresh consumption: A comparison between Italian landraces and commercial varieties. Agriculture, 9, 253, 1-14.

Deiana, M., Rosa, A., CaO, C.F., Pirisi, F.M., Bandino, G. \& Dessi̊̊, M.A. (2002): Novel approach to study oxidative stability of extra virgin olive oils: importance of $\alpha$-tocopherol concentration. J. Agr. Food Chem., 50, $4342-4346$.

Harrabi, S., Ferchichi, A., Bacheli, A. \& Fellah, H. (2018): Policosanol composition, antioxidant and antiarthritic activities of milk thistle (Silybium marianum L.) oil at different seed maturity stages. Lipids Health Dis., $17,82$.

Harrabi, S., Romdhane, H., DaAsSa, M. \& Fellah, H. (2015): Fatty acid and triacylglycerol compositions of milk thistle seeds growing wild in Tunisia (Silybum marianum L.). Acta Alimentaria, 44, 304-310.

Harrabi, S., Sakouhi, F., St-Amand, A., Boukhchina, S., Kallel, H. \& MaYer, P.M. (2007): Accumulation of phytosterols, triterpene alcohols and phytostanols in developing Zea mays L. kernels. J. Plant Sci., 2, 260 272.

Hedley, C. (2001): Introduction. -in: Hedley, C. (Ed.): Carbohydrates in grain legume seeds: Improving nutritional quality and agronomic characteristics. CABI Publishing, New York; pp. 1-11.

Jiang, Q., Christen, S., Shigenaga, M.K. \& Ames, B.N. (2001): Gamma-tocopherol, the major form of vitamin E in the US diet, deserves more attention. Am. J. Clin. Nutr., 74, 714-722. 
Lu, Y., Tian, Сh., Gao, Сh., Wang, B., Yang, W., ... \& He, Y. (2018): Phenolic composition, antioxidant capacity and inhibitory effects on $\alpha$-glucosidase and lipase of immature faba bean seeds. Int. J. Food Prop., 21, 23662377.

Malenčić, Đ. Kiprovski, B., Bursić, V., Vukovic, G., Ćupina. B. \& Mikic, A. (2018): Dietary phenolics and antioxidant capacity of selected legumes seeds from the Central Balkans. Acta Alimentaria, 47, 340-349.

MANJUR, A.S., RAYHANA, B., KOLAPPA, K.P., vidHU, A., SHOWKAT, R.M., ... \& MANJU, S. (2016): In vitro $\alpha$-glucosidase and $\alpha$-amylase inhibition by aqueous, hydroalcoholic, and alcoholic extract of Euphorbia hirta L. Drug. Dev. Ther., 2016(7), 26-30.

Prabakaran, R., Pranav, N., Pradeep, K., Jeyakumar, K. \& Bibin, J. (2016): Antimicrobial activities of selected four less known pulses. BMRJ, 15(1), 1-8.

Quan, N.V., Xuan, T.D., Tran, H.D., Thuy, N.T.D., Trang, L.T., ... \& TuYen, P.T. (2019): Antioxidant, $\alpha$-amylase and $\alpha$-glucosidase inhibitory activities and potential constituents of Canarium tramdenum bark. Molecules, 24(3), 605.

Shahzad, N., Khan, W., Md, S., Ali, A,. Saluja, S.S., ... \& Al-Ghamdi, S.S. (2017): Phytosterols as a natural anticancer agent: Current status and future perspective. Biomed. Pharmacother., 88, 786-794.

Telagari, M. \& Hullatti, K. (2015): In-vitro $\alpha$-amylase and $\alpha$-glucosidase inhibitory activity of Adiantum caudatum Linn. and Celosia argentea Linn. extracts and fractions. Indian J. Pharmacol., 47, 425-429.

Zhou, W, Branch, W.D., Gilliam, L. \& Marshal, J.A. (2019): Phytosterol composition of Arachis hypogaea seeds from different maturity classes. Molecules, 2410106. 